Journal of Animal and Veterinary Advances 11 (5): 578-582, 2012

ISSN: $1680-5593$

(C) Medwell Journals, 2012

\title{
New SNPs of the Duck $L P L$ Gene are Associated with Body Weight, Fatness and Carcass Traits
}

\author{
Yongping Yang, Ping Gong, Shijun Li, Xiuli Peng, Yanping Feng and Yanzhang Gong \\ Key Laboratory of Agricultural Animal Genetics, Breeding and Reproduction, \\ Ministry of Education, Huazhong Agricultural University, \\ Wuhan, 430070 Hubei, P.R. China
}

\begin{abstract}
Lipoprotein Lipase (LPL) is a multifunctional protein that plays a major role in the hydrolysis of triglycerides present in chylomicrons and very low-density lipoproteins. This study was designed to investigate the effects of Single Nucleotide Polymorphisms (SNPs) of the duck $L P L$ gene on fatness and carcass and growth traits. A White Kaiya $\mathrm{x}$ White Liancheng $\mathrm{F}_{2}$ population with a total of 1069 individuals was used in the present study, 440 healthy ducks randomly selected from this population were slaughtered at 80 days of age. PCR-Single Strand Conformation Polymorphism (PCR-SSCP) and sequencing methods were used to detect SNPs in the duck $L P L$ gene. Two new SNPs (C645T and G726A) were discovered in exons 5 and genotyped using the PCR-Restriction Fragment Length Polymorphism (PCR-RFLP) Method. Genotyping results showed that the genotype distribution differed between males and females, thus the association analyses were performed separately for males and females. Association analyses indicated that the SNPs were significantly associated with body weight, fatness and carcass traits ( $\mathrm{p}<0.05$ or $\mathrm{p}<0.01$ ). We concluded that LPL is a major gene or is linked with a major gene that influences body weight, fatness and carcass traits and that C645T and G726A could be used as candidate molecular genetic markers for breeding selection.
\end{abstract}

Key words: Duck, LPL, SNP, body weight, fatness, carcass, PCR-SSCP, PCR-RFLP

\section{INTRODUCTION}

Duck breeding for the harvesting of meat has advanced considerably in recent decades, resulting in reduced slaughter age and greatly increased feed efficiency, meat production and growth rate. The intensive selection for growth rate however has led to increased body fat deposition which has become one of the main problems facing the duck breeding industry. Excessive fat deposition affects duck carcass appearance and meat quality and it also causes low feeding efficiency, environmental pollution and food safety problems.

Lipoprotein Lipase (LPL) plays a central role in normal lipid metabolism. It is the key enzyme involved in the hydrolysis of triglycerides present in chylomicrons and very low-density lipoproteins. LPL is related to adipose tissue fat deposition (Hermier et al., 1989, 1991) and Frayn et al. (1995) reported that it mediates fat deposition and mobilization in white adipose tissue. Sato et al. (1999) successfully reduced chicken body fat by injecting anti-LPL antibody into chickens, thereby illustrating that LPL plays an important role in fat deposition. Many studies have used the $L P L$ gene to detect polymorphisms associated with adipose traits (including abdominal fat weight, subcutaneous fat weight, thickness of subcutaneous fat and intermuscular fat width) in chickens, pigs and other animals (Harbitz et al., 1992; Lei et al., 2004; Liu et al., 2006). In ducks, Wu et al. (2008) discovered a single nucleotide polymorphism (SNP; $\mathrm{C} / \mathrm{T}$ alteration) in exon 7 of the $L P L$ gene and found that it was associated with abdominal fat weight in native and Cherry Valley Peking duck however, no association was found between the SNP and subcutaneous fat plus skin weight and carcass traits.

To further study the $L P L$ gene and to find a molecular marker that could be used for marker-assisted selection in duck breeding, we screened the polymorphisms of the duck $L P L$ gene and studied the associations of polymorphisms with body weight, carcass and fatness traits in the study population.

\section{MATERIALS AND METHODS}

Animals and samples: In collaboration with Jingwu Food Industrial Garden Ltd., (Wuhan, China), a White Kaiya $\mathrm{x}$ White Liancheng $\mathrm{F}_{2}$ population with a total of 1069

Corresponding Author: Yanzhang Gong, Key Laboratory of Agricultural Animal Genetics, Breeding and Reproduction, Ministry of Education, Huazhong Agricultural University, Wuhan, 430070 Hubei, P.R. China 
Table 1: Primers designed for amplification of the $L P L$ gene

\begin{tabular}{|c|c|c|c|c|}
\hline Primer name & Primer sequence $\left(5^{\prime}-3^{\prime}\right)$ & Annealing temp $\left({ }^{\circ} \mathrm{C}\right)$ & Product locus & Product size (bp) \\
\hline Lexon2F & AGCACGAAGCTGAGACGAAT & 58 & Exon 2 & 170 \\
\hline Lexon2R & CGTCCATCCATGGATGACCA & & & \\
\hline Lexon3F & GTGACAGGCATGTATGAAAGTT & 56 & Exon 3 & 180 \\
\hline Lexon3R & CTCCATCCAGTCAATAAACATAG & & & \\
\hline Lexon5F & GGGCCCACCTTTGAGTAC & 58 & Exon 5 & 219 \\
\hline Lexon5R & TGCAAGGCCTTTTTCAGC & & & \\
\hline Lexon6F & GTGGATCAGCTGGTGAAATG & 57 & Exon 6 & 238 \\
\hline Lexon6R & TGTAGGGCATCTGAGCACG & & & \\
\hline Lexon8F & GCCAGAAGTCTCCTCAAACA & 56 & Exon 8 & 183 \\
\hline Lexon8R & TTTTTCTGAGTTTCGCCTGA & & & \\
\hline
\end{tabular}

individuals was used in the present study. All birds were raised in floor pens and fed standard commercial corn-soybean diets. Body weight was recorded every 2 weeks from birth to the 12 th weeks. Individual blood samples were collected and genomic DNA was extracted using a standard phenol; chloroform extraction method these samples then were stored at $-20^{\circ} \mathrm{C}$. At 80 days of age, 440 healthy ducks randomly selected from this population were slaughtered. Three kinds of fatness traits were measured; abdominal fat weight, subcutaneous fat plus skin weight and thickness of subcutaneous fat. The following conventional carcass traits were measured as well: body weight (before slaughter), carcass weight, eviscerated with giblet weight, eviscerated weight, breast muscle weight (right side) and leg muscle weight (right side). In China, people also eat the head, neck, wings, palma and some of the organs. Thus, based on the characteristics of the Chinese duck products market, head weight, neck weight, wing weight (right side), shank plus palma weight, heart weight, liver weight and muscular stomach weight also were measured.

SNP identification and PCR-RFLP analysis: The cDNA sequence of the duck $L P L$ gene that we obtained from a normalized cDNA library was submitted to the GenBank database under the accession no. FJ859348. Using this sequence, five pairs of primers were designed using the software Primer Premier 5.0 (Premier, Palo Alto, CA, USA) (Table 1).

All PCRs were performed in Mastercycler ep gradient $\mathrm{S}$ (Eppendorf, Hamburg, Germany) using the following cycling parameters; $94^{\circ} \mathrm{C}$ initial denaturation for $7 \mathrm{~min}$, 32 cycles of $94^{\circ} \mathrm{C}$ denaturing for $40 \mathrm{sec}, 56-58^{\circ} \mathrm{C}$ (Table 1) annealing for $40 \mathrm{sec}$ and $72^{\circ} \mathrm{C}$ extension for $40 \mathrm{sec}$, followed by a $7 \mathrm{~min}$ extension at $72^{\circ} \mathrm{C}$.

PCR-Single Strand Conformation Polymorphism (PCR-SSCP) was used to detect polymorphisms with the following procedure; PCR products were denatured at $98^{\circ} \mathrm{C}$ for $10 \mathrm{~min}$ and rapidly chilled on ice. Next, $4 \mu \mathrm{L}$ of PCR product mixed with $10 \mu \mathrm{L}$ loading buffer were loaded on 10\% PAGE gels $(39: 1)$ at $4^{\circ} \mathrm{C}$ at an initial voltage of $300 \mathrm{~V}$ for $10 \mathrm{~min}$ then $110 \mathrm{~V}$ for $16 \mathrm{~h}$. Results were visualized by silver staining. Based on the different band patterns, the PCR products were isolated and purified then cloned into pGEM-T vectors (Promega, Madison, WI, USA) and sequenced.

Two new SNPs were discovered in exons 5 and genotyped using the PCR-Restriction Fragment Length Polymorphism (PCR-RFLP) Method. PCR products of exon 5 were digested respectively with $4 \mathrm{U}$ of Sac II and $4 \mathrm{U}$ of Mva I (MBI, Vilnius, Lithuania) in $10 \mu \mathrm{L}$ reaction solutions overnight at $37^{\circ} \mathrm{C}$ following the supplier's directions. The digested products were detected by electrophoresis on $2.0 \%$ agarose gel stained with ethidium bromide and visualized using a gel imaging system (BIO-RAD, Hercules, CA, USA).

Statistical analysis: The distribution of genotypes differed between sexes in this study and the traits analyzed also differed significantly between sexes ( $<<0.05$ ). Moreover, the $L P L$ gene might be a $z$-linked gene. Therefore, the association analyses between the SNPs and traits were performed separately for males and females using the $t$ statistic and the SPSS 13.0 statistical software package (SPSS Inc., Chicago, IL, USA).

\section{RESULTS AND DISCUSSION}

Discovery of new SNPs in the $L P L$ gene: All fragments were successfully amplified. Two new SNPs, C645T and G726A were discovered in exon 5 through sequence comparison (Fig. 1). The SNPs were synonymous and caused restriction enzyme sites change (SacII and MvaI) and did not result in an amino acid change.

SNP genotyping using PCR-RFLP: The presence of three genotypes, CC (132 and 87 bp), CT (219, 132 and 87 bp) and TT (219 bp) was revealed by a PCR-RFLP Method using the SacII restriction enzyme at C645T (Fig. 2a). Three genotypes, AA (168 and 51 bp), AG (219, 168 and $51 \mathrm{bp})$ and GG (219 bp) were revealed using the PCR-MvaI-RFLP method at G726A (Fig. 2b). 
(a) $\mathrm{CACC} \mathrm{CGCG} \mathrm{G} \mathrm{C} \mathrm{TC} \mathrm{TCCA}$

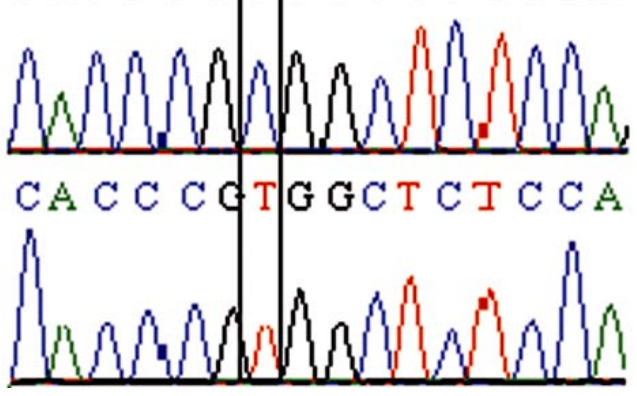

(b)

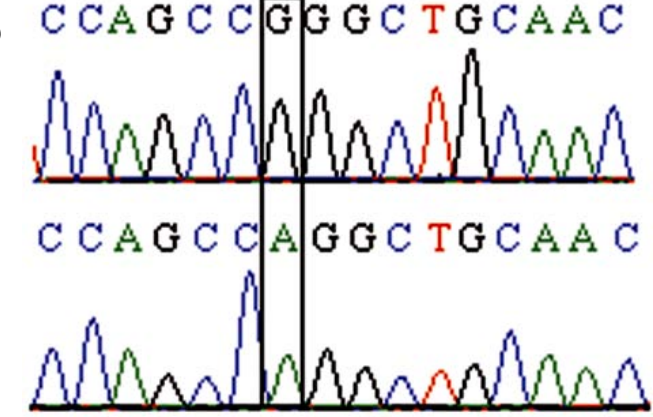

Fig. 1: Sequence analysis revealed two new SNPs in the $L P L$ gene; a) $\mathrm{C} / \mathrm{T}$ mutation in exon 5 at position 645 ; b) G/A mutation in exon 5 at position 726

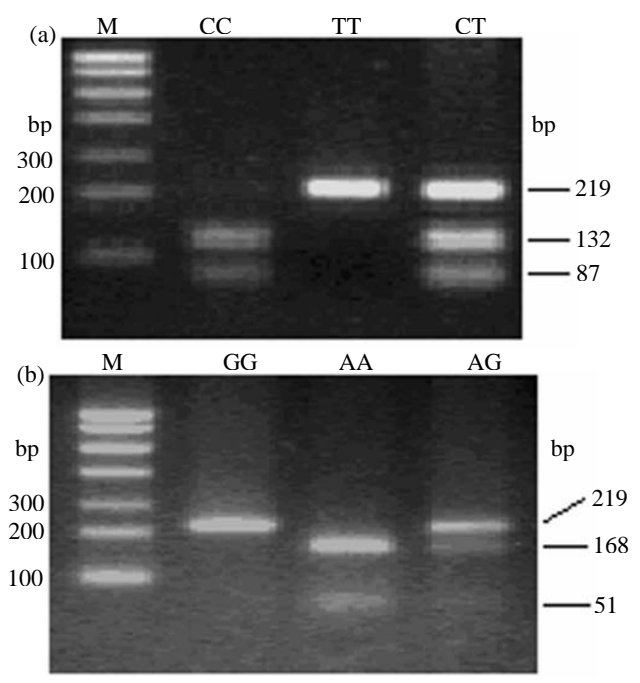

Fig. 2: PCR-RFLP patterns of the $L P L$ gene resolved by agarose gel electrophoresis; a) Genotyping of the LPL gene at C645T using the PCR-SacII-RFLP Method. M: DNA marker; CC: CC genotype; TT: TT genotype; CT:CT genotype; b) Genotyping of the $L P L$ gene at G726A using the PCR-MvaI-RFLP Method. M: DNA marker; GG: GG genotype; AA: AA genotype; AG: AG genotype
Table 2: Genotype distribution of SNPs differed between males and females

\begin{tabular}{lcccr}
\hline & Genotype & & & \\
& ------------ & Total \\
Sex & CC (GG) & CT (AG) & TT (AA) & 469 \\
Male & 389 & 80 & 0 & 600 \\
Female & 589 & 0 & 11 & \\
\hline
\end{tabular}

Genotyping results showed that the genotypes of the two SNP loci completely corresponded to each other with $\mathrm{CC}$ corresponding to $\mathrm{GG}$, TT corresponding to AA and CT corresponding to AG (Fig. 2). Therefore, the genotypes $\mathrm{CC}$ and $\mathrm{GG}$ were combined into one genotype $\mathrm{CC}$ (GG), TT and AA were combined into TT (AA) and CT and AG were combined into CT (AG). The distribution of genotypes differed between males and females (Table 2). Only two genotypes, CC (GG) and CT (AG) were detected in males whereas only $\mathrm{CC}$ (GG) and TT (AA) were detected in females. Thus, the association analyses were performed separately for males and females.

Association and effect of SNPs on body weight, fatness and carcass traits: The association analysis result between SNPs and body weight is shown in Table 3. In males, the body weight of genotype CT (AG) was significantly higher than that of CC (GG) from 8-12 weeks $(p<0.01)$. In females, the body weight of genotype TT (AA) was significantly higher than that of $\mathrm{CC}(\mathrm{GG})$ from 4-12 weeks $(\mathrm{p}<0.05$ or $\mathrm{p}<0.01)$.

The association analyses results of SNPs and fatness and carcass traits are shown in Table 4. In males, the fatness and carcass trait values of genotype CT (AG) were significantly higher than those of $\mathrm{CC}(\mathrm{GG})(\mathrm{p}<0.05$ or $\mathrm{p}<0.01$ ), except for thickness of subcutaneous fat $(\mathrm{p}=0.225)$. In females, the fatness and carcass trait values of genotype TT (AA) were significantly higher than those of $\mathrm{CC}(\mathrm{GG})(\mathrm{p}<0.05$ or $\mathrm{p}<0.01)$ except for head weight, abdominal fat weight and thickness of subcutaneous fat $(\mathrm{p}>0.05)$.

These results indicate that these two SNPs (C645T and $\mathrm{G} 726 \mathrm{~A}$ ) of the duck $L P L$ gene are significantly associated with body weight, fatness and carcass traits; the effect of the duck LPL gene on body weight appears earlier in females than in males and trait values for genotypes CT (AG) and TT (AA) are all higher than those of the $\mathrm{CC}(\mathrm{GG})$ genotype in both males and females and the alleles $\mathrm{T}$ (A) were associated with an increase in the trait values.

LPL is an important marker for adipocyte differentiation (Bjorntorp et al., 1978) and LPL expression increases in parallel with cellular triglyceride accumulation as preadipocytes differentiate (Semenkovich et al., 1989). Although, adipose tissue can synthesize free fatty acids de novo, free fatty acids for lipid storage are preferentially 
Table 3: Association analysis of SNPs with body weight

\begin{tabular}{|c|c|c|c|c|c|c|}
\hline \multirow[b]{3}{*}{ Weeks } & \multicolumn{2}{|l|}{ Male } & \multirow[b]{3}{*}{$\mathrm{p}$-value } & \multicolumn{2}{|l|}{ Female } & \multirow[b]{3}{*}{ p-value } \\
\hline & \multicolumn{2}{|l|}{ Genotype $(\mu \pm \mathrm{SD}, \mathrm{g})$} & & \multicolumn{2}{|l|}{ Genotype $(\mu \pm \mathrm{SD}, \mathrm{g})$} & \\
\hline & $\mathrm{CC}(\mathrm{GG})(\mathrm{n}=389)$ & $\mathrm{CT}(\mathrm{AG})(\mathrm{n}=80)$ & & $\mathrm{CC}(\mathrm{GG})(\mathrm{n}=589)$ & $\mathrm{TT}(\mathrm{AA})(\mathrm{n}=11)$ & \\
\hline Birth & $44.9 \pm 4.900$ & $44.9 \pm 4.400$ & 0.991 & $45.8 \pm 4.600$ & $47.2 \pm 3.400$ & 0.340 \\
\hline 2 & $330.8 \pm 69.50$ & $345.8 \pm 71.80$ & 0.090 & $340.1 \pm 68.80$ & $350.9 \pm 49.30$ & 0.605 \\
\hline 4 & $883.3 \pm 151.1$ & $899.5 \pm 159.6$ & 0.412 & $882.9 \pm 144.9$ & $973.0 \pm 68.30$ & 0.050 \\
\hline 6 & $1393.2 \pm 247.3$ & $1416.8 \pm 238.4$ & 0.437 & $1389.7 \pm 227.4$ & $1563.6 \pm 130.8$ & 0.012 \\
\hline 8 & $1748.4 \pm 244.5$ & $1868.5 \pm 281.0$ & 0.000 & $1694.3 \pm 240.3$ & $1965.5 \pm 160.8$ & 0.000 \\
\hline 10 & $1848.7 \pm 242.0$ & $2032.8 \pm 265.2$ & 0.000 & $1805.2 \pm 227.8$ & $2121.5 \pm 98.30$ & 0.000 \\
\hline 12 & $1815.7 \pm 243.1$ & $1999.7 \pm 270.7$ & 0.000 & $1849.5 \pm 214.0$ & $2205.5 \pm 234.1$ & 0.020 \\
\hline
\end{tabular}

Table 4: Association analy sis of SNPs with fatness and carcass traits

\begin{tabular}{|c|c|c|c|c|c|c|}
\hline \multirow[b]{3}{*}{$\underline{\text { Traits }}$} & \multicolumn{3}{|l|}{ Male } & \multicolumn{3}{|l|}{ Female } \\
\hline & \multicolumn{2}{|l|}{ Genotype $(\mu \pm \mathrm{SD})$} & \multirow[b]{2}{*}{$\mathrm{p}$-value } & \multicolumn{2}{|l|}{ Genotype $(\mu \pm \mathrm{SD})$} & \multirow[b]{2}{*}{ p-value } \\
\hline & $\mathrm{CC}(\mathrm{GG})(\mathrm{n}=206)$ & CT $(A G)(n=40)$ & & $\mathrm{CC}(\mathrm{GG})(\mathrm{n}=187)$ & $\mathrm{TT}(\mathrm{AA})(\mathrm{n}=7)$ & \\
\hline Body weight (before slaughter) (g) & $1638.8 \pm 218.8$ & $1856.2 \pm 239.0$ & 0.000 & $1637.8 \pm 198.5$ & $1986.6 \pm 143.1$ & 0.000 \\
\hline Carcass weight $(\mathrm{g})$ & $1432.9 \pm 189.1$ & $1621.7 \pm 209.6$ & 0.000 & $1443.2 \pm 175.9$ & $1733.2 \pm 159.2$ & 0.000 \\
\hline Eviscerated with giblet weight (g) & $1302.2 \pm 182.1$ & $1476.9 \pm 207.5$ & 0.000 & $1324.9 \pm 162.1$ & $1586.6 \pm 137.9$ & 0.000 \\
\hline Eviscerated weight $(\mathrm{g})$ & $1196.3 \pm 167.0$ & $1357.3 \pm 189.3$ & 0.000 & $1213.3 \pm 148.0$ & $1437.9 \pm 104.5$ & 0.000 \\
\hline Leg muscle weight (right side) (g) & $95.4 \pm 12.3$ & $105.9 \pm 14.2$ & 0.000 & $93.0 \pm 11.6$ & $105.0 \pm 7.0$ & 0.007 \\
\hline Breast muscle weight (right side) (g) & $81.1 \pm 14.9$ & $94.9 \pm 16.4$ & 0.000 & $82.2 \pm 13.6$ & $102.4 \pm 9.8$ & 0.000 \\
\hline Head weight (g) & $87.9 \pm 8.5$ & $94.2 \pm 9.3$ & 0.000 & $80.6 \pm 7.9$ & $85.4 \pm 5.9$ & 0.112 \\
\hline Neck weight (g) & $95.2 \pm 12.8$ & $106.1 \pm 14.4$ & 0.000 & $88.0 \pm 11.6$ & $102.7 \pm 8.9$ & 0.001 \\
\hline Wing weight (right side) (g) & $62.7 \pm 8.7$ & $69.7 \pm 8.7$ & 0.000 & $60.9 \pm 8.1$ & $71.1 \pm 5.8$ & 0.001 \\
\hline Shank plus palma weight (g) & $20.1 \pm 2.6$ & $22.9 \pm 3.3$ & 0.000 & $19.6 \pm 2.6$ & $21.6 \pm 1.6$ & 0.050 \\
\hline Heart weight (g) & $12.6 \pm 1.9$ & $14.1 \pm 1.9$ & 0.000 & $12.6 \pm 1.7$ & $15.0 \pm 1.8$ & 0.000 \\
\hline Liver weight (g) & $32.8 \pm 7.8$ & $37.1 \pm 9.0$ & 0.002 & $33.5 \pm 6.8$ & $51.1 \pm 20.7$ & 0.000 \\
\hline Muscular stomach weight (g) & $45.7 \pm 7.7$ & $52.6 \pm 7.1$ & 0.000 & $44.2 \pm 7.1$ & 54.77 .6 & 0.000 \\
\hline Abdominal fat weight (g) & $13.2 \pm 7.4$ & $16.1 \pm 8.6$ & 0.029 & $21.4 \pm 9.9$ & $28.7 \pm 13.9$ & 0.060 \\
\hline Subcutaneous fat plus skin weight (g) & $244.1 \pm 56.9$ & $280.4 \pm 67.4$ & 0.000 & $295.2 \pm 55.4$ & $374.9 \pm 77.9$ & 0.000 \\
\hline Thickness of subcutaneous fat $(\mathrm{cm})$ & $0.397 \pm 0.113$ & $0.421 \pm 0.101$ & 0.225 & $0.456 \pm 0.110$ & $0.507 \pm 0.084$ & 0.229 \\
\hline
\end{tabular}

provided by LPL-mediated hydrolysis of plasma TG-rich lipoproteins (Hollenberg, 1966). Thus, LPL is considered to be a gatekeeper enzyme that plays an important role in the initiation and/or development of obesity and that relates to energy balance insulin action and body weight regulation (Wang and Eckel, 2009). The candidate gene approach is a powerful method to investigate associations between gene polymorphisms and economically important traits in farm animals (Rothschild and Soller, 1997). Many studies have examined the effect of polymorphisms of the $L P L$ gene on fatness traits in different species (Ginzinger et al., 1999; Harbitz et al., 1992; Hata et al., 1992; Lei et al., 2004; Liu et al., 2006; Petersonet al., 2002; Reymer et al., 1995; Wu et al., 2008). Genetic markers associated with fat deposition are used to assist in selection for meat quality and production efficiency in chickens (Liu et al., 2006). In this study, the $L P L$ gene was selected as a candidate gene to investigate associations of gene polymorphisms with body weight, fatness and carcass traits in a White Kaiya $\mathrm{x}$ White Liancheng $\mathrm{F}_{2}$ population.

A $\sim 1.3 \mathrm{~kb}$ cDNA sequence of the duck $L P L$ gene was generated from a normalized cDNA library that we constructed previously (GenBank accession no. FJ859348). We screened this sequence and detected two new SNPs in exons 5 using PCR-SSCP and DNA sequencing methods. The SNPs were genotyped by PCRRFLP using SacII and MvaI, respectively. The genotypes of the two SNPs completely corresponded to each other indicating that these two SNPs were completely linked.

However, no localization information exists for the $L P L$ gene in the duck. The $L P L$ gene is located on chromosome Z in Gallus gallus and on chromosome Z in another bird, Taeniopygia guttata. Much research has shown strong chromosome homology between macrochromosomes in different bird species (Masabanda et al., 2004). Therefore, on the basis of the chromosome location of the LPL gene in G. gallus and $T$. guttata, the strong chromosome homology among different bird species and the lack of a heterozygote in females in the study, we suspect that the duck $L P L$ gene also might be localized on chromosome $\mathrm{Z}$.

In this study, two new SNPs from exon 5 were genotyped. Association analyses of these SNPs with body weight, fatness and carcass traits were performed separately for males and females. The results showed significant differences in body weight, fatness and carcass traits between different genotypes $(\mathrm{p}<0.05$ or $\mathrm{p}<0.01)$. 


\section{CONCLUSION}

This finding indicates that the SNPs (C645T and G726A) in the LPL gene were significantly associated with these traits. Thus, the $L P L$ gene may be a major gene or may be linked to a major gene that affects duck body weight, fatness and carcass traits. These SNPs can be used in molecular marker-assisted selection as a genetic marker for duck breeding.

\section{ACKNOWLEDGEMENTS}

This research was financially supported by the Project for Critical Technology during the Eleventh 5 years Plan of Hubei Province (2006AA202A04), the Key Project for Industrialization during the Eleventh 5 years Plan in Wuhan (20062001017) and the National Project for the Support of Science and Technology (2008BADB2B 08).

\section{REFERENCES}

Bjorntorp, P., M. Karlsson, H. Pertoft, P. Pettersson, L. Sjostrom and U. Smith, 1978. Isolation and characterization of cells from rat adipose tissue developing into adipocytes. J. LipidRes., 19: 316-324.

Frayn, K.N., S.W. Coppack, B.A. Fielding and S.M. Humphreys, 1995. Coordinated regulation of hormone-sensitive lipase and lipoprotein lipase in human adipose tissue in vivo: Implications for the control of fat storage and fat mobilization. Adv. Enzyme Regul., 35: 163-178.

Ginzinger, D.G., S.M. Clee, J. Dallongeville, M.E. Lewis and H.E. Henderson et al., 1999. Lipid and lipoprotein analysis of cats with lipoprotein lipase deficiency. Eur. J. Clin. Invest., 29: 17-26.

Harbitz, I., T. Kristensen, S. Kran and W. Davies, 1992. Isolation and sequencing of porcine lipoprotein lipase cDNA and its use in multiallelic restriction fragment length polymorphism detection. Anim. Genet., 23: 517-522

Hata, A., D.N. Ridinger, S.D. Sutherland, M. Emi and L.K. Kwong et al., 1992. Missense mutations in exon 5 of the human lipoprotein lipase gene. Inactivation correlates with loss of dimerization. J. Biol. Chem., 267: 20132-20139.

Hermier, D., A. Quignard-Boulange, I. Dugail, G. Guy and M.R. Salichon et al., 1989. Evidence of enhanced storage capacity in adipose tissue of genetically fat chickens. J. Nutr., 119: 1369-1375.
Hermier, D., M.R. Salichon and C.C. Whitehead, 1991. Relationships between plasma lipoproteins and glucose in fasted chickens selected for leanness or fatness by three criteria. Reprod. Nutr. Dev., 31: 419-429.

Hollenberg, C.H., 1966. The origin and glyceride distribution of fatty acids in rat adipose tissue. J. Clin. Invest., 45: 205-216.

Lei, M.G., Y.Z. Xiong, C.Y. Deng, Z.F. Wu, I. Harbitz, B. Zuo and L.H. Dai, 2004. Sequence variation in the porcine lipoprotein lipase gene. Anim. Genet., 35: 422-423.

Liu, R., Y. Wang, D. Sun, Y. Yu and Y. Zhang, 2006. Association between polymorphisms of lipoprotein lipase gene and chicken fat deposition. AsianAustralasian J. Anim. Sci., 19: 1409-1414.

Masabanda, J.S., D.W. Burt, P.C.M. O'Brien, A. Vignal and V. Fillon et al., 2004. Molecular cytogenetic definition of the chicken genome: The first complete avian karyotype. Genetics, 166: 1367-1373.

Peterson, J., A.F. Ayyobi, Y. Ma, H. Henderson and M. Reina et al., 2002. Structural and functional consequences of missense mutations in exon 5 of the lipoprotein lipase gene. J. Lipid Res., 43: 398-406.

Reymer, P.W., E. Gagne, B.E. Groenemeyer, H. Zhang and I. Forsyth et al., 1995. A lipoprotein lipase mutation (Asn291Ser) is associated with reduced HDL cholesterol levels in premature atherosclerosis. Nat. Genet., 10: 28-34.

Rothschild, M. and M. Soller, 1997. Candidate gene analysis to detect genes controlling traits of economic importance in domestic livestock. Probe, 8: 13-20.

Sato, K., Y. Akiba, Y. Chida and K. Takahashi, 1999. Lipoprotein hydrolysis and fat accumulation in chicken adipose tissues are reduced by chronic administration of lipoprotein lipase monoclonal antibodies. Poult. Sci., 78: 1286-1291.

Semenkovich, C.F., M. Wims, L. Noe, J. Etienne and L. Chan, 1989. Insulin regulation of lipoprotein lipase activity in 3T3-L1 adipocytes is mediated at posttranscriptional and posttranslational levels. J. Biol. Chem., 264: 9030-9038.

Wang, H. and R.H. Eckel, 2009. Lipoprotein lipase: From gene to obesity. Am. J. Physiol. Endocrinol. Metab., 297: E271-E288.

Wu, Y., H.L. Zhang, J. Wang and X.L. Liu, 2008. Discovery of a SNP in exon 7 of the lipoprotein lipase gene and its association with fatness traits in native and Cherry Valley Peking ducks. Anim. Genet., s39: 564-566. 